\title{
New map of tsunami-hazard for the south Kuril Islands
}

\author{
Georgy Shevchenko ${ }^{1, *}$, Artyom Loskutov ${ }^{1}$ and Victor Kaystrenko ${ }^{1}$ \\ ${ }^{1}$ Institute of Marine Geology and Geophysics of Far East Branch of Russian Academy of Sciences, \\ 1B Nauki str, 693022, Yuzhno-Sakhalinsk, Russia
}

\begin{abstract}
The tsunami-zoning map (possible tsunami heights of a frequency of 1 event within 50 and 100 years) for the coast of the South Kuril Islands have been updated (former map have been developed in 2006). The update is based on the development of the tsunami-activity model, mainly due to the increase of the number of basic coastal locations (from 18 to 62) for which the parameters of the recurrence function were estimated, as well as on the modernization of the numerical model. Serious progress in simulations was achieved in setting the initial conditions, using the seismic tsunami source model. Field surveys on the coast to search for traces of historical and paleotsunami, as well as qualitative documentation of the Tohoku tsunami manifestations allowed to clarify the model of tsunamiactivity in Southern Kuril Islands. The sufficiently large amount of data in this case (which is generally untypical for the tsunami) allowed authors, to apply the statistical approach for evaluation of the tsunami hazard distribution along the coast. Estimates of tsunami heights were spread from the basic coastal locations to adjacent parts of the coast using detailed simulation of all significant tsunamis and calculating wave heights at the shoreline. The detailed maps of tsunami-hazard at scale 1:100,000 have been made for the settlements of Yuzhno-Kurilsk, Kurilsk, Malokurilskoe, and Krabozavodskoe.
\end{abstract}

\section{Introduction}

Tsunami is one of the most formidable natural phenomena of nature, which causes great damage to economic objects of coastal settlements of the Far Eastern region of Russia, and sometimes to human casualties. The term "tsunami" is Japanese and means "big wave in the harbor".

Tsunami is a long wave (more often a train, or a group of such waves), which is usually caused by movements of the ocean floor around a strong underwater earthquake. The Kuril Islands as well as Kamchatka peninsula, are located near to one of the most seismically active regions in the world, which is confined to the western slope of the Kuril trench. It is here, where the epicenters of tsunamigenic (tsunami-inducing) earthquakes are located, the corresponding map is shown in fig 1 . The southern Kuril Islands are especially outstanding

\footnotetext{
*Corresponding author: shevchenko_zhora@mail.ru
} 
by the frequency of such events. About 20 earthquakes have been recorded here over the last 100 years or so. Just this circumstance allows us to apply the statistical approach [1], based on the reconstruction of a probabilistic tsunami-regime model and the simulation of the most dangerous tsunami to estimate the tsunami hazard in the region. Based on the same principle, the previous map was constructed in 2006. In present work, the map actualization was carried out due to information on tsunami manifestations in the past 11 years (several events were recorded, of which the Tohoku Tsunami on 11.03.2011 was a danger for settlements of the southern Kuril Islands), the determination of the heights of some historical tsunamis during field surveys along the coast, and the development of methods for numerical simulation.

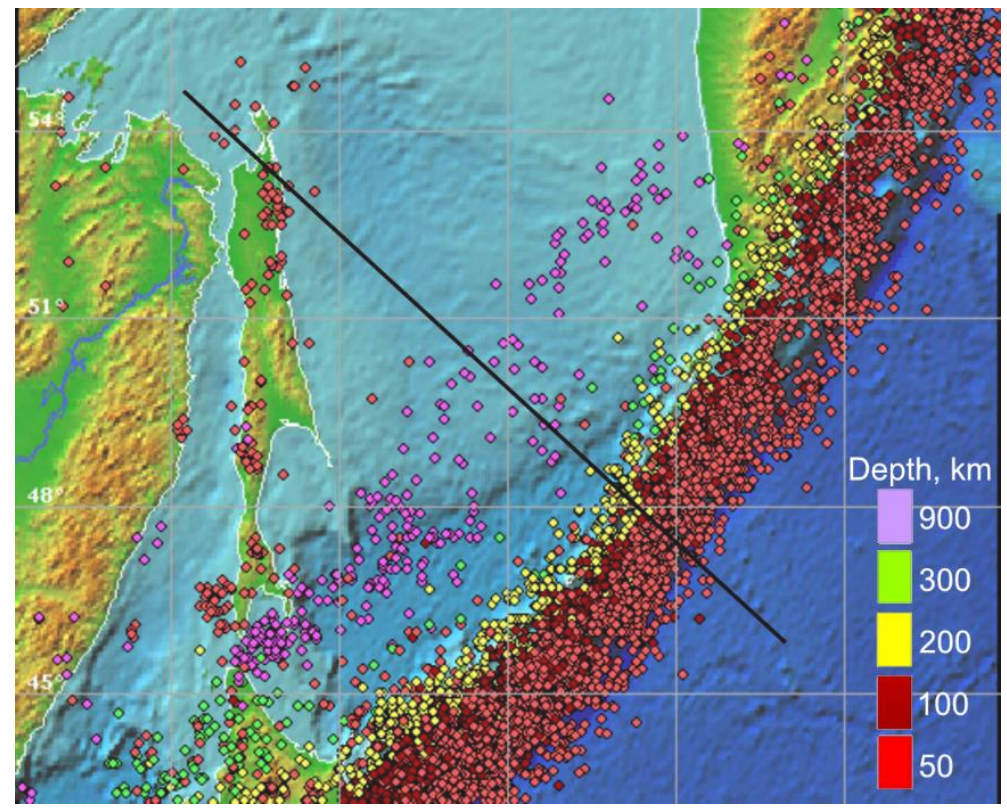

Fig. 1. The distribution of earthquake epicenters along the Kuril trench.

\section{Data and tsunami hazard assessment technique}

\subsection{Regional tsunami-recurrence function}

The tsunami hazard assessment technique is based on estimation of regional tsunamirecurrence function (the number of significant tsunamis, exceeded height $h$ within time $T$ at some point $x$ of coast) [1]:

$$
\varphi(x, h)=\frac{n}{T}=f(x) \Phi\left(x, \frac{h}{H *}\right)
$$

which parameters are $f$, the frequency of strong tsunamis in region and $H^{*}$, the local intensity of tsunami on a given coast segment. This information is generally known for the settlements as well as for the places where special field surveys of the coastal areas most affected by the tsunami were carried out.

As soon as parameters of the recurrence function are determined, the wave height for the given period of repeatability $\mathrm{T}$ is determined by the formula $[1,2]$

$$
h_{T}=H^{*} \ln (T f)
$$


Created in 2006 tsunami-zoning maps for the southern Kuril Islands [3,4] were based on data of historical tsunamis maximum heights recorded during the period 1953-2005 (52 years) in 18 coastal settlements. For these settlements the estimates of the most important parameters which are the average frequency of strong tsunamis in the region, equals to 0.17 cases per year with a relative error of $13 \%$, as well as the values of the characteristic heights $H^{*}$ for all 18 settlements were obtained. At this time, additional data has been obtained on recent tsunamis and old ones. The data expanded the "skeleton" of the new tsunami hazard map, which is now based on data on the manifestations of real tsunamis in 63 points on the coast of the Southern Kuril Islands. In fact, one parameter, the average frequency of tsunamis in the region is the same for all points of the considered coast, its refined value is 0.16 cases per year with a relative error of $11 \%$, which is in a good agreement for all settlements with the most representative series of observations [1].

The heights of the 7 most significant tsunamis in the main settlements of the Southern Kuril Islands are shown in the Table 1 . These events determine the level of tsunami danger in the studied region and were given the most attention through the rest of the work.

Table 1. Tsunami heights (in meters) of the most significant tsunamis in the main settlements of the southern Kuril Island.

\begin{tabular}{|c|c|c|c|c|c|c|c|}
\hline \multirow{2}{*}{ Settlement } & \multicolumn{7}{|c|}{ Year } \\
\cline { 2 - 9 } & 1958 & 1960 & 1963 & 1969 & 1975 & 1994 & 2011 \\
\hline Iturup Island, Burevestnik & 3.0 & 2.5 & 1.5 & 1.0 & 0.4 & 2.3 & 2.1 \\
\hline Iturup Island, Kurilsk & & 1.0 & 0.7 & 0.6 & & 0.3 & 0.3 \\
\hline Kunashir Island, Yuzhno-Kurilsk & 2.5 & 2.2 & 1.0 & 1.1 & 0.6 & 4.0 & 2.2 \\
\hline Kunashir Island, Sernovodnoye & 2.5 & & 1.0 & & & 1.6 & 1.6 \\
\hline Shikotan Island, Malokurilskoye & 3.5 & 4.0 & 1.5 & 1.0 & 0.6 & 2.5 & 1.6 \\
\hline Shikotan Island, Malokurilskoye & 5.0 & & 2.5 & 1.0 & 1.5 & 2.6 & 1.5 \\
\hline
\end{tabular}

\subsection{Extension of recurrence function to the adjacent areas of the coast}

To develop tsunami hazard map, one needs extend estimates of tsunami heights from base observation points (generally, placed very irregular and near settlements) to adjacent areas of the coast. For that purpose, all significant tsunamis, which determine characteristics of tsunami risk and parameters of probability model of tsunami-regime, are simulated.

To simulate the tsunamis adequate tsunami source models, built on the base of new seismological information and formulae [5], are necessary. With the formulae one can estimate vertical displacement of sea bed in the source of underwater earthquake. Herewith, one can achieve a good similarity of simulated waveforms not only to the deep-sea NOAA DART records, but also to majority of offshore records, using information about earthquake mechanism and other parameters, as it was shown for the Tohoku tsunami in [6].

The situation with the tsunami sources of the past is much more difficult as there's a lack of information necessary to estimate source parameters.

These events considered in [7,8], also parameters of those source models reviewed in $[9,10,11]$. The exact match of observed and simulated tsunami heights is not necessary, as shown in [12] only height ratio estimates are enough for the point where tsunami height is known. Since there are many control points, the correctness of the ratio can be verified by the good correlation between the calculated tsunami heights and observed heights in the control points (though, the data is enough for quantification of latest 1994 and 2011 events, 
only qualitative assessment is possible for earlier evets). Whereupon, it becomes possible to build recurrence function at any point, using transfer coefficients, herewith the structure of seismic source according to modern authors let us count on adequate spatial distribution of the transfer coefficients regardless whether the height of the vertical displacement in the source has been understated or not.

\subsection{Characteristics of numerical model}

The paper uses a custom modification of the program code that implements the leap-frog finite difference scheme for linear equations of shallow water in spherical coordinates, created and freely distributed by the famous Japanese expert F. Imamura with a group of coauthors [13]. The simulations were carried out on uniform grids, and all fields were described by two-dimensional arrays. Computational procedures were parallelized for a hybrid cluster with graphics accelerators. This allowed each tsunami calculation to accelerate by at least an order of magnitude, and simultaneously calculate up to 10 tsunamis at a time.

For simulations we used publicly available array of depths from the base SRTM15 [14]. To conduct detailed simulations in bays of Shikotan Island and refine calculation in YuzhnoKurilskaya Bay and Kitoviy Bay of Iturup Island the 15-arcsecond grid has been interpolated for coupling with digitized bathymetries of bays to 2 -arcsecond resolution. The seismological finite-fault data of tsunamigenic earthquakes were taken from USGS and articles devoted to old events of 1958-1994 [15, 9,10,11, 16]. After carrying out calculations of the propagation of all significant tsunamis, the numerical waveforms in each point along the isobath of about $8 \mathrm{~m}$ were processed with a special transformation allowing one to estimate the wave height on the shore with assumption the one-dimensional nonlinear rolling. Then the characteristic height $H^{*}$, recalculated with respect to the new regional frequency $f=0.16$ events per year to the tsunami run-up repeatability of 100 years was estimated with the obtained arrays of runup. Thus, the $\mathrm{h}_{100}$-distribution was constructed along the whole coast of Southern Kuril Islands.

\section{Discussion}

\subsection{The Shikotan tsunami of 5 October 1994}

Let's consider features of manifestations, source parameters and simulation results for one of the dangerous events in the region, the Shikotan tsunami of 5 October 1994. Figure 2 shows a map with the boundaries of the inundation area of the main settlement - YuzhnoKurilsk. The southern part of the city and the areas adjacent to the channel of the Serebryanka River were severely affected, the bridge through which was destroyed (Fig. 3).

Around the meteorological station, in the northern part of the South Kurile Bay, the instrumentally measured height of the run-up was $2.9 \mathrm{~m}$, and the range was $20 \mathrm{~m}$. The coast in this region is steep, with surface and underwater rocks. During the tsunami, a passenger ship was thrown ashore. A detailed description of the consequences of the tsunami on the Kunashir and Shikotan islands is given in [17,18]. 


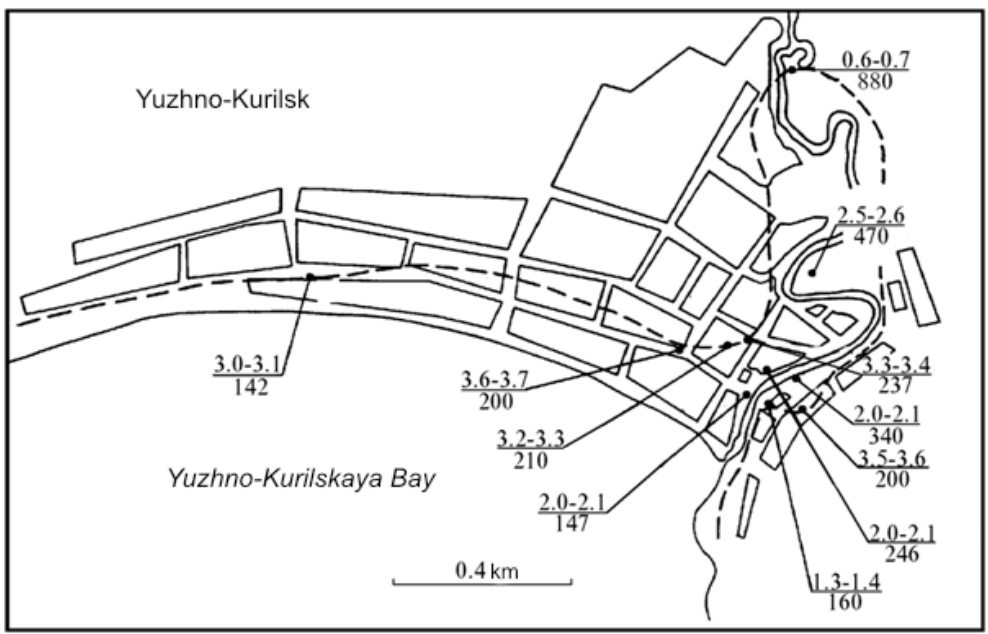

Fig. 2. The boundary of the inundation in the city of Yuzhno-Kurilsk. Numbers are the heights (numerator) and range (in the denominator) of the run-ups, in meters.

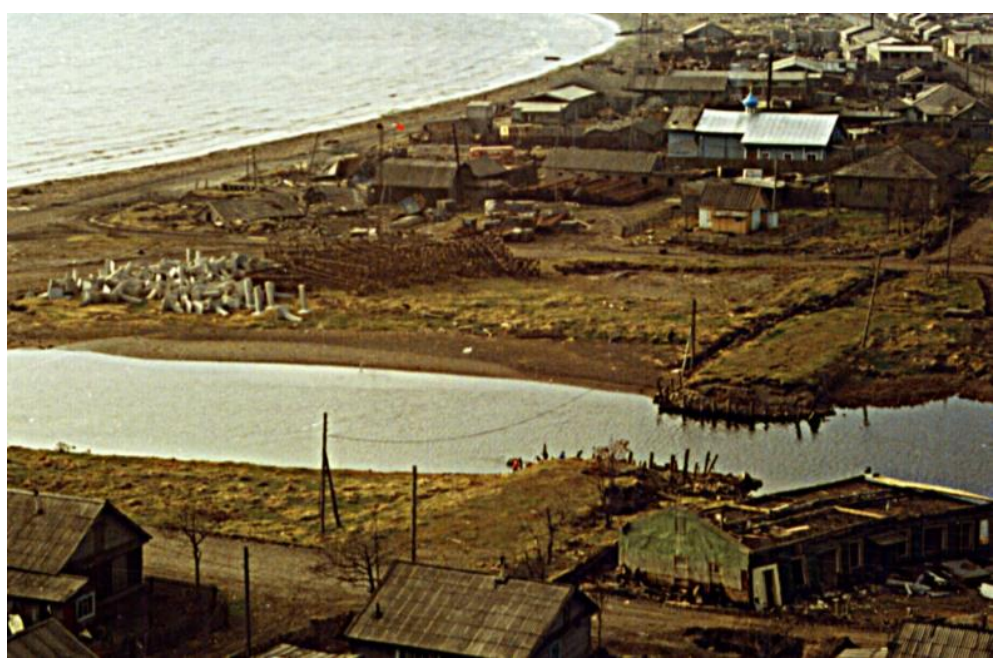

Fig. 3. The part of Yuzhno-Kurilsk that was affected by tsunami attack. Photo by A.N. Korablev.

We used the source model given in [15] with 4 elementary blocks, the displacement of which was determined by inversion of tsunami records and geodetic data (Fig. 4). The Shikotan Island itself was in the zone of descending the earth's crust $(-53 \mathrm{~cm}$ according to the model), which agrees well with observations of vertical displacements of the island [19].

The distribution of the maximum wave heights along the coast is given according to the results of the simulation in figure 5. As expected, the highest run-ups were at the ocean side of Shikotan Island. In Bezymjannaya Bay run-up reached 8.5 meters $(7.7 \mathrm{~m}$ according to field observation), also high values of run-up obtained in Tserkovnaya and Neshoba Bays. High enough values, which was not observed during the Shikotan tsunami of 11.081969 and 10.06.1975 (run-up according to the survey results was about $3 \mathrm{~m}$ ) were on the south side of the island, in the Dolphin Bay. The coincidence of simulations and observations is quite good in Malokurilskaya, Otradnaya and Krabovaya Bays. In the last Bay significant differences of simulated heights, like those revealed within consequences assessment of 1994 tsunami, were obtained. 


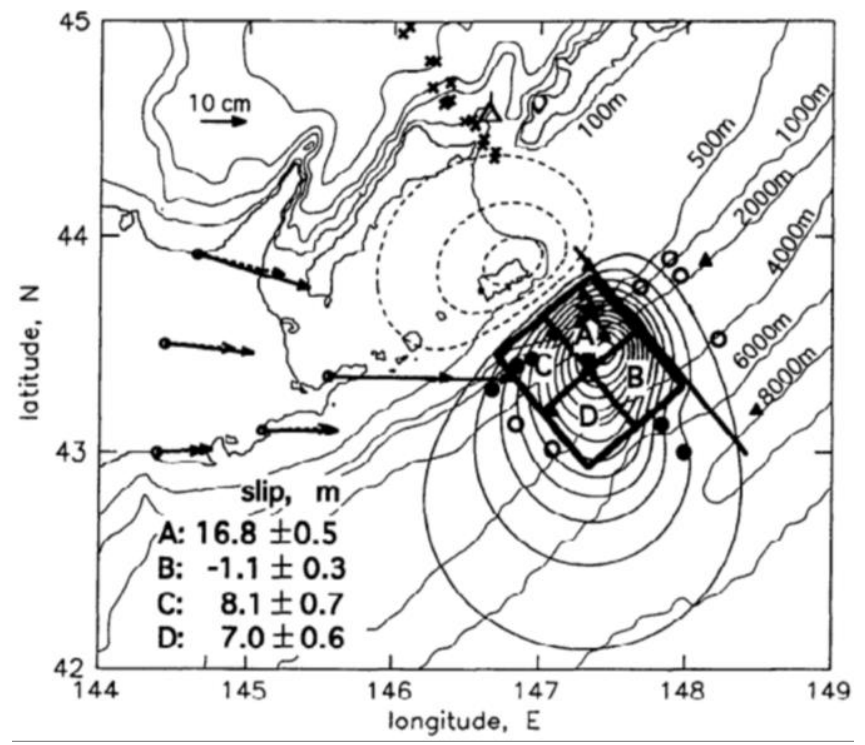

Fig. 4. Source model of the Shikotan tsunami according to [15] with 4 elementary blocks.

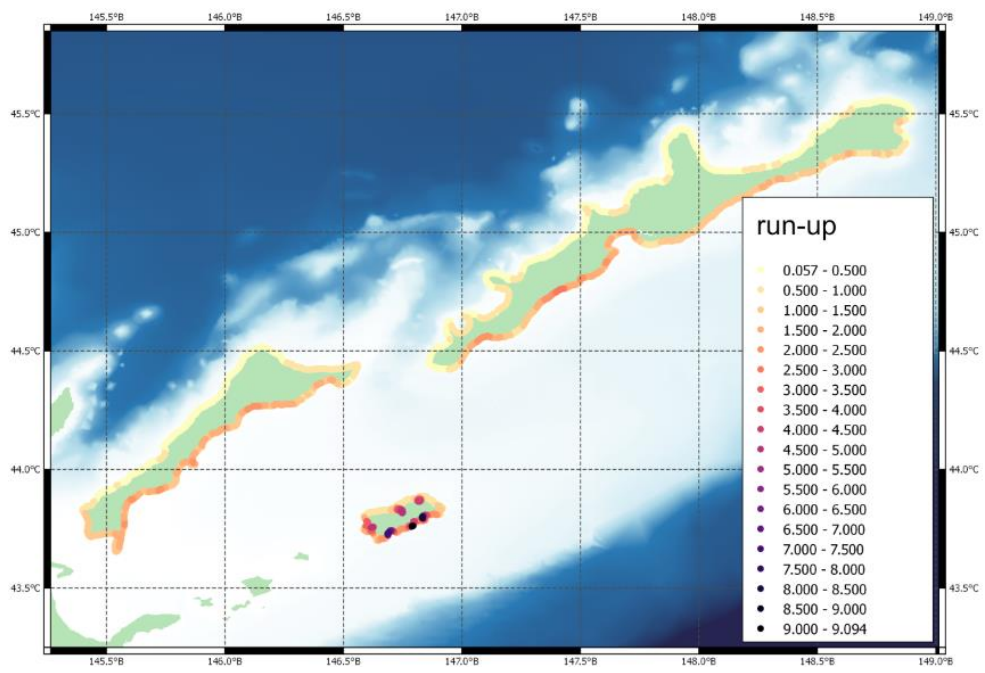

Fig. 5. Distribution of the heights of the Shikotan Tsunami on October 5, 1994 on the coast of the South Kuril Islands according to numerical modeling.

Similarly, the run-up distributions of 7 most significant tsunamis was obtained within analogous numerical experiments. For a such rare events like dangerous tsunamis this kind of statistics is very representable and allows to infer parameter $\mathrm{H}^{*}$ (while the mean frequency of tsunamis in the region we consider constant value $\mathrm{f}=0.16$ events per year, because its changes were negligible after precising the tsunami recurrence function). Then parameter $\mathrm{H}^{*}$ estimated for each coast point using tuple of 7 calculated run-ups, that let us to calculate needed value of run-up of 1 event per 50 and 100 years recurrence, the $\mathrm{H}_{50}$ and $\mathrm{H}_{100}$. Results for $\mathrm{H}_{100}$ are presented on figure 6 . 


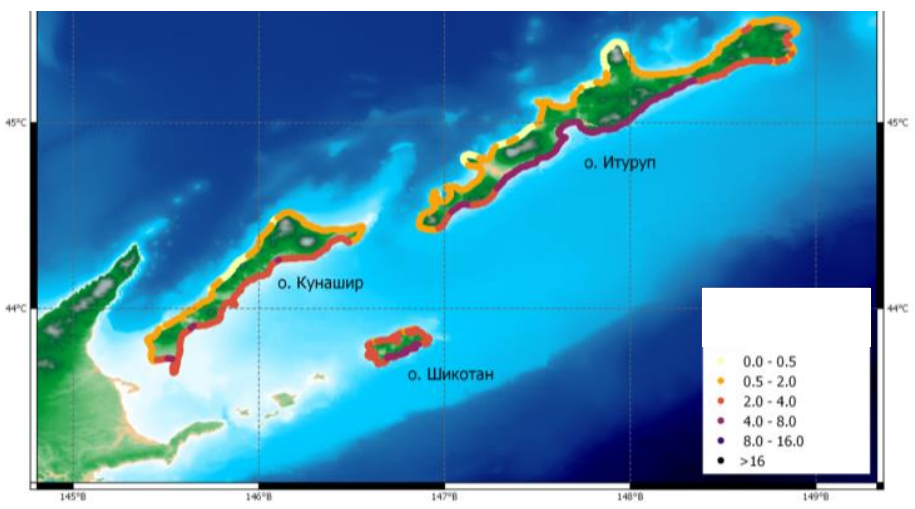

Fig. 6. The 1:1000000 map of distribution of possible run-ups of 1 event per 100 years recurrence for Southern Kuril Islands.

In recently published prescriptive document [2] related to building construction in tsunami-hazardous area, it is recommended to use the next tsunami height scale when showing tsunami maps:

Table 2. Height scale.

\begin{tabular}{|c|c|}
\hline Less than $0.5 \mathrm{~m}$ & Insignificant \\
\hline $0.5-1 \mathrm{~m}$ & Very weak / perceptible \\
\hline $1-2 \mathrm{~m}$ & Weak \\
\hline $2-4 \mathrm{~m}$ & Moderate / harmful \\
\hline $4-8 \mathrm{~m}$ & Strong / significantly damaging \\
\hline $8-16 \mathrm{~m}$ & Very strong / destructive \\
\hline More than $16 \mathrm{~m}$ & Catastrophic / devastating \\
\hline
\end{tabular}

We followed this style guide in present work, the only difference is in one more $6 \mathrm{~m}$ grade between $4 \mathrm{~m}$ and $8 \mathrm{~m}$. Also, we didn't separate insignificant and perceptible tsunamis, as from the practical point of view it does not make sense, so on map we provided joined range of tsunami height less than $1 \mathrm{~m}$. There were no simulated run-ups higher than $16 \mathrm{~m}$, so we left only range of run-ups above $8 \mathrm{~m}$ height.

As we expected the highest run-ups were estimated for the Pacific coast of Shikotan Island. At Snezhkova and Dimitrova Bays run-up were about 8-10 m, a bit less in Tserkovnaya Bay. On the previous map, published in 2006, estimated run-ups on this area were significantly smaller at level around $4 \mathrm{~m}$. The increasing correction of the run-up looks approved since observed run-up after 5 October 1994 tsunami was $7 \mathrm{~m}$. Thus, it is possible to say that we achieved a very important refinement of a previous estimate, because of using more detailed bottom grid, which allowed us to conduct simulations with respect to real underwater topography of Bays where the significant amplifications of tsunami due to resonance effects happens. On the part of the South Kurile Strait, as well as on the northern and southern coasts of the island, the degree of tsunami hazard is significantly lower, although the Malokurilskaya and Krabovaya Bays stand out against the general situation, which will be discussed in more detail below.

The second most dangerous area is the Pacific coast of Iturup island, primarily Kasatka Bay, where estimated run-ups decrease both directions from the Bay. High degree of tsunami hazard in the Bay of Burevestnik port were shown even on previous map. The high degree 
of danger in the Bay is determined foremost by the tsunami of 1958, which source was exactly opposite to Iturup Island. However, the run-up at port was much less than expected (about 3 $\mathrm{m})$. Thus, with an implementation of scenario approach to tsunami risk assessment [20], tsunami height estimates up to $15 \mathrm{~m}$, with parameters and location of tsunami source close to real event, were obtained on the Pacific coast of the Island. Relatively small for a such strong earthquake tsunami height are probably related to deeper hypocenter location than used in simulation. But, for all scenarios of simulation has been made during development of previous map 4] and in present work calculated run-up were significantly higher. One should consider high degree of danger of tsunami in this region disregard the features of generation of the tsunami of 1958 .

Om figure 7 the detailed map of tsunami height distribution at scale 1:1000000 is presented for Krabovaya and Malokurilskaya Bays coasts. For the bays a special simulation on detailed depth grids with spatial step of 2 arcseconds with nesting algorithm was conducted. The figures show the whole coast of the Island, but special simulation ran only for mentioned Bays, for other cases simulation was carried out on 15-arcsecobd grids, which characteristics discussed earlier. In the case of Krabovaya Inlet, it is clearly seen the increase of tsunami height distribution of repeatability once in 50 years while moving deep from the mouth. The presence of amplitude antinode in the inlet's crest, traditionally considered to be the safest place, is well known feature of the resonant oscillations in harbours. But what is true for storm is not in case of long gravity waves like tsunamis. So, it is possible to claim that port constructions and near-coast part of Krabozavodskoe settlement are under possible tsunami hazard. The same features are clearly revealed at Malokurilskaya Bay. Despite the differences in the geometric shapes of the bays (long narrow inlet type and pear-shaped with a narrow entrance), the resonance oscillations of the main modes with periods of about 29 and 19 minutes have a decisive influence on the degree of tsunamis danger of their coast. The constructed maps can be used in the development of urban planning documentation (territorial planning schemes, urban zoning and planning documentation) for the sustainable and safe development of tsunami dangerous areas in the Southern Kuril Islands.

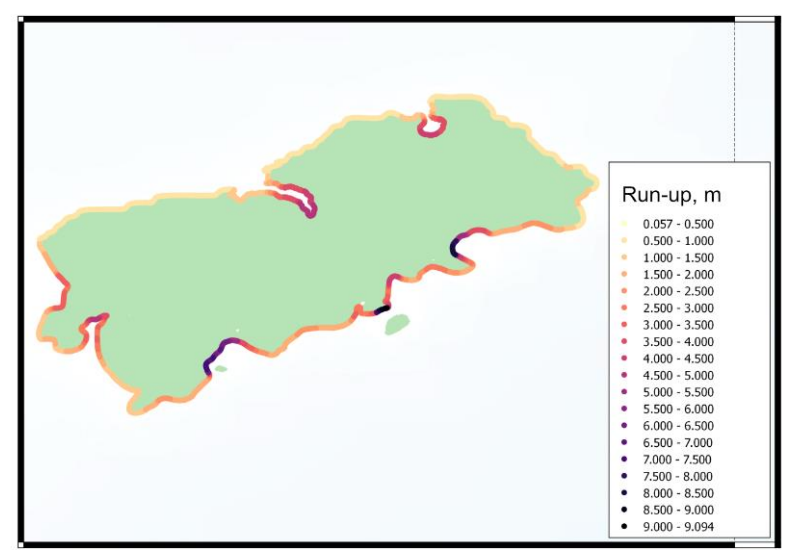

Fig. 7. Wave heights of tsunami repeatability of once per 100 years for the coast of Shikotan. Detailed map of scale 1:100000 of the coast of Malokurilskaya and Krabovaya Bays (the village Malokurilskoe and Krabozavodskoe).

\section{Conclusion}

In the present work the refined statistical tsunami activity model based on new data on strong tsunami events in the Southern Kuril Islands is presented. The more detailed tsunami recurrence function was estimated by use of new high performance computational 
techniques, cluster resources and high-quality seismic and bottom relief data. The actual maps of tsunami hazard based on the new assessment of regional tsunami probability and the tsunami recurrence function are developed. The results of the work are suitable for both tsunami hazard mitigation and producing recommendations for new buildings and infrastructure improvements near shore This research was supported in through computational resources provided by the Shared Facility Center "Data Center of FEB RAS" (Khabarovsk) [21].

\section{References}

1. V.M. Kaistrenko, PAGEOPH 171(12), 3527-3538 (2014)

2. Russian Standard SP 292.1325800.2017

3. Assessment of tsunami risk of sea coastal area. Compilation of the map of tsunami risk for Sakhalin region at scale 1:200000, Report on scientific research (IMGG FEB RAS, 2006)

4. IGRAS, PGI FEB RAS, RFBR, Atlas of the Kuril Islands (LLC "PPC "DIK", 2009)

5. Y. Okada, Bull. Seism. Soc. Am. 75, 1435-1154 (1985)

6. G.V. Shevchenko, T.N. Ivelskaya, A.V. Loskutov, PAGEOPH 171, 3329-3350 (2014)

7. Ch.U. Kim, M.Yu. Andreeva, Earthquake catalogue (1737-2005) (IMGG FEB RAS, 2009)

8. L.N. Poplavskaya, M.I. Rudik, M.I. Nagornykh, et.al. Catalogue of strong earthquakes source mechanisms $(M \geq 6.0)$ of Kuril-Okhotsk region in 1964-2009 (IMGG FEB RAS, 2009)

9. K. Ioki, Y. Tanioka, Relations of great Kurile earthquakes estimated from tsunami waveforms, Abstracts of 7-th Int. symposium of Int. tsunami society in Davos (2008)

10. K. Ioki, Y. Tanioka, Pure Appl. Geophys 168, 1045-1052 (2011)

11. K. Ioki, Y. Tanioka, Pure Appl. Geophys 173, 4179-4187 (2016)

12. V.N. Khramushin, G.V. Shevchenko, A tsunami zoning technique by Aniva bay example, Oceanology, 218-223 (1994)

13. F. Imamura, A. C. Yalciner, G. Ozyurt, Tsunami modelling manual 58 (2006)

14. J. Becker, D. T. Sandwell, W. H. F. Smith, et.al. Marine Geodesy 32, 355-371 (2009)

15. Y. Tanioka, L. Ruff, K. Satake, Geophys. Research letters 22, 1661-1664 (1995)

16. M.S. Moreno, J. Bolte, J. Klotz, D. Melnick, Geophys. Res. Letters 36, 373-377 (2009)

17. Y.P. Korolev, L.D. Zhukov, N.D. Zolotukhin, et.al. The specific Manifestations of the tsunami. Tsunami of 1993 and 1994 on the coast of Russia (IMGG FEB RAS, 1997)

18. V.M. Kaistrenko, V.K. Gusyakov, V.A. Dzhumagaliev, et.al. The specific Manifestations of the tsunami. Tsunami of 1993 and 1994 on the coast of Russia (IMGG FEB RAS, 1997)

19. N.F. Vasilenko, O.S. Sedaeva, V.P. Semakin, G.V. Shevchenko, The great Shikotan earthquake and tsunami 4(5) October 1994. Chronicles, analysis of consequences and the actual condition of the problem: manuscript collection (IMGG FEB RAS, 2014)

20. G.V. Shevchenko, D.E. Zolotukhin, I.N. Tikhonov, Scientific and educational problems of the civil defense 1, 21-30 (2011)

21. A.A. Sorokin, S.I. Makogonov, S.P. Korolev, Scientific and Technical Information Processing 4, 302-304 (2017) 